\title{
OBSERVATIONS ON REPRODUCTION IN THE MONGOLIAN GERBIL, MERIONES UNGUICULATUS
}

\author{
G. E. ADAMS AND M. L. NORRIS \\ Agricultural Research Council, Unit of Reproductive Physiology and Biochemistry, \\ University of Cambridge*
}

(Received 30th November 1972)

Since introducing the Mongolian gerbil to our laboratory in 1965, we have accumulated a variety of data concerning the reproduction of this species. The present report is based on the 4-year period, 1967-70.

Details of the origins and management of our colony have been given elsewhere (Norris \& Adams, 1972a). Breeding stock were kept as monogamous pairs. If no litter resulted within 3 months of pairing, a different male was introduced and, whenever necessary, this procedure was repeated after a further 3 months. If the female still proved barren, autopsy was performed. Any males or females which showed a strong tendency to behave aggressively were culled. Routine procedures, such as inspection of cages for litters and taking vaginal smears, were carried out twice daily at 09.00 to 09.30 hours and 17.00 to 17.30 hours. Vaginal smears were taken on Day 1 (Day $0=$ day of parturition) with the aid of a fire-polished glass rod in preference to the lavage technique. All young were removed at birth.

The mean age at pairing of the 224 females that we observed was $127 \pm 7$ days, range 60 to 272 days, and the mean interval from pairing to parturition was 90 days, range 24 to 250 days, indicating a mean delay of some 65 days before pregnancy was successfully initiated. The interval between subsequent parturitions was considerably shorter, being $48 \pm 3,52 \pm 5,47 \pm 4,42 \pm 3$ and $40 \pm 6$ days for the first to sixth parturitions. The tendency for the mean interval to decrease as the litter number increased from two to six is attributed to the elimination of less successful females from the breeding population. Recently, we have established that the age and previous sexual experience of the male influences the interval from pairing to the first successful mating (Norris \& Adams, 1972b). Since all young were removed soon after birth, the parturition intervals are not complicated by the occurrence of delayed implantation, which may extend gestation up to 48 days (Norris \& Adams, 1971).

Twelve females which failed to produce a litter were killed 9 months after the initial pairing; three were found to have cystic ovaries (see Norris \& Adams, 1972c) but otherwise the genital tract appeared normal in every case. In six of the twelve females, corpora lutea were present.

In a sample of 144 litters, $124(86 \%)$ were produced between 17.30 hours and 09.00 hours, including seven where parturition was still in progress at 09.30

* Postal address : 307 Huntingdon Road, Cambridge CB3 0JQ. 
hours. Of the remaining twenty cases, eighteen were produced between 09.30 hours and 17.30 hours with two in progress at 17.30 hours.

The incidence of mating post partum was determined after 144 parturitions in a total of eighty-one females. On several occasions, we observed females showing lordosis at 17.30 hours on the day of parturition but, though copulation appeared to occur, spermatozoa were never found in the smear. However, spermatozoa were found the following morning (Day 1) at 09.00 hours. Altogether, 109 matings $(76 \%)$ were detected on Day 1 . Among the remaining thirty-five females, seven subsequently littered following a gestation consistent with

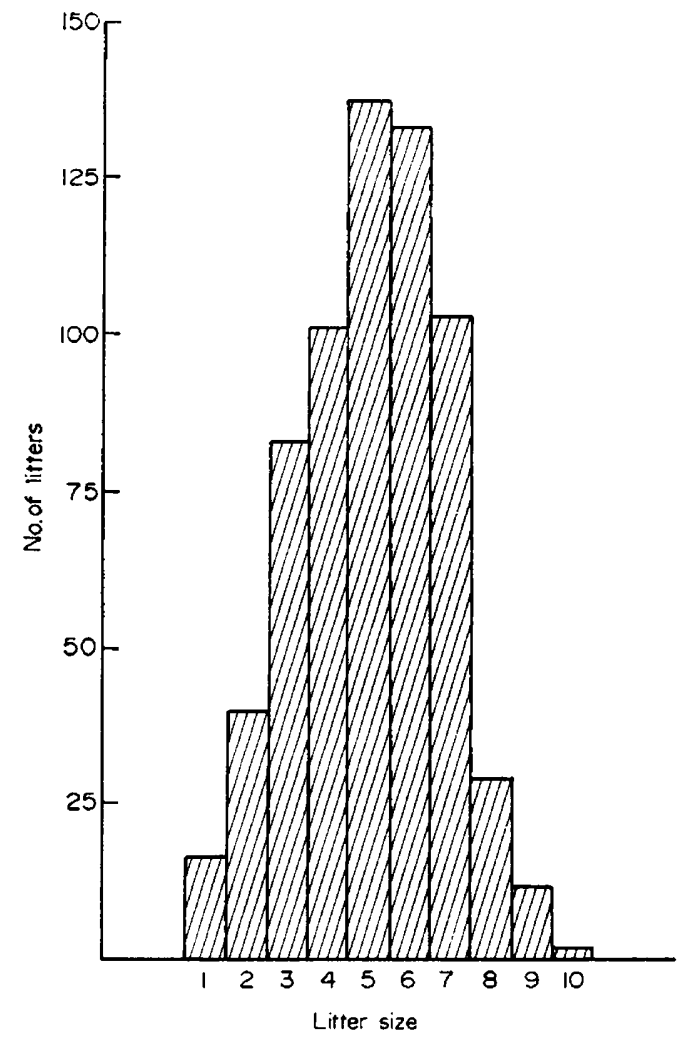

Text-fig. 1. The distribution of 657 litters according to size in the Mongolian gerbil, Meriones unguiculatus.

mating having occurred within 3 days of parturition. Altogether, therefore, at least $80 \%(116 / 144)$ of the animals mated and of these, ninety-three $(80 \%)$ littered. Schwentker (1963) noted that oestrus occurred post partum and that $60 \%$ of the females became pregnant at that time. Similar figures were reported by Marston \& Chang (1965), who found that $59 \%$ of their animals mated post partum and of these, $86 \%$ were fertile as judged on the basis of the recovery of fertilized eggs or completion of pregnancy.

The cellular changes noted in the vaginal smear taken post partum were comparatively regular. On Day 0 , the smear tended to contain few cells, those 
present being predominantly cornified with some epithelial cells, a few leucocytes and occasional red cells. On Day 1, if spermatozoa were found-and these were rarely motile - the smear consisted almost entirely of cornified cells with a few epithelial cells and only rarely were leucocytes present. When spermatozoa were absent, the smear was much more variable; it was usually thick with many leucocytes and epithelial cells. A striking feature was the rapidity with which spermatozoa were eliminated from the vagina: commonly, the smear was negative at 17.30 hours in animals that had shown a positive smear at 09.00 hours.

Altogether, 657 litters were recorded during the 4-year observation period. In individual years, the mean litter sizes were 4.4 (1 to 9 ), 5.2 ( 1 to 9 ), 5.0 (1 to 10 ) and 5.2 ( 1 to 9 ), based on 66, 201, 228 and 162 litters, respectively. The distribution of the 657 litters according to size is illustrated in Text-fig. 1. The majority $(85 \%)$ of the litters contained from three to seven young, with a litter size of one accounting for less than $3 \%$ of the total. Earlier reports on litter size include those of Nakai, Nimura,Tamura, Shimizu \& Nishimura (1960), Schwentker (1963) and Marston \& Chang (1965), who recorded 4·8 $\pm 0 \cdot 9,4 \cdot 1$ (1 to 12 ) and $4.5 \pm 0.04$, respectively.

Table 1. The effect of age of the female on mean litter size in the Mongolian gerbil

\begin{tabular}{c|c|c|c}
\hline $\begin{array}{c}\text { Age range } \\
\text { (days) }\end{array}$ & $\begin{array}{c}\text { No. of } \\
\text { observations }\end{array}$ & Litter size & $\begin{array}{c}\text { Mean parity } \\
\text { of female }\end{array}$ \\
\hline$<99$ & 9 & $4 \cdot 1 \pm 0 \cdot 5(2$ to 7$)$ & $1 \cdot 0 \pm 0 \cdot 0$ \\
100 to 199 & 74 & $5 \cdot 1 \pm 0 \cdot 2(1$ to 9$)$ & $1 \cdot 5 \pm 0 \cdot 1$ \\
200 to 299 & 111 & $5 \cdot 2 \pm 0 \cdot 2(1$ to 10$)$ & $2 \cdot 2 \pm 0 \cdot 1$ \\
300 to 399 & 80 & $4 \cdot 7 \pm 0 \cdot 2(1$ to 9$)$ & $2 \cdot 6 \pm 0 \cdot 1$ \\
400 to 499 & 16 & $4 \cdot 3 \pm 0 \cdot 6(1$ to 8$)$ & $3 \cdot 1 \pm 0 \cdot 3$ \\
\hline
\end{tabular}

Values expressed as Means \pm S.E.; ranges in parentheses.

In the 290 cases where the exact ages of the females were known, it was possible to examine the effect of age on litter size. There was an initial rise from 4.1 in females aged less than 100 days to 5.1 in those aged 100 to 199 days. Litter size was well maintained up to 300 days of age but thereafter, a decline was noted (Table 1). In agreement with the earlier report of Marston \& Chang (1965), litter size appeared to be very little influenced by parity; means of $5.0 \pm 0.2(112), 5 \cdot 0 \pm 0.2(82), 4.8 \pm 0.3(50), 5 \cdot 1 \pm 0.3(29)$ and $5 \cdot 4 \pm 0.3(17)$ were recorded for litters from the first to the sixth parturition. Nakai et al. (1960) noted that the first litter was the smallest but their total material contained only twenty-seven litters.

The sex ratio (males per 100 females) based on 1824 young in 367 litters was 102.4. An earlier report, based on fifty-seven litters containing 280 young, gave 102.9 (Marston \& Chang, 1965).

Observations on the incidence of dead young soon after birth were made on 430 litters, twelve of which contained a total of thirteen dead young, equivalent to $0.6 \%$ of the 2160 young born. Two-thirds of the dead young were found to have been still-born: the remainder must have died soon after birth. Cannibalism was not observed. 
Where the length of gestation was accurately known (eighty-six pregnancies), it varied from 24 to 26 days which accords with earlier reports. The proportions of females littering on Days 24, 25 and 26 were $33 \%, 39 \%$ and $28 \%$ and the mean litter sizes were 5.5 (1 to 9 ), 4.4 ( 1 to 7 ) and 3.3 (1 to 7 ), respectively. The relationship between length of gestation and litter size is depicted in Text-fig. 2.

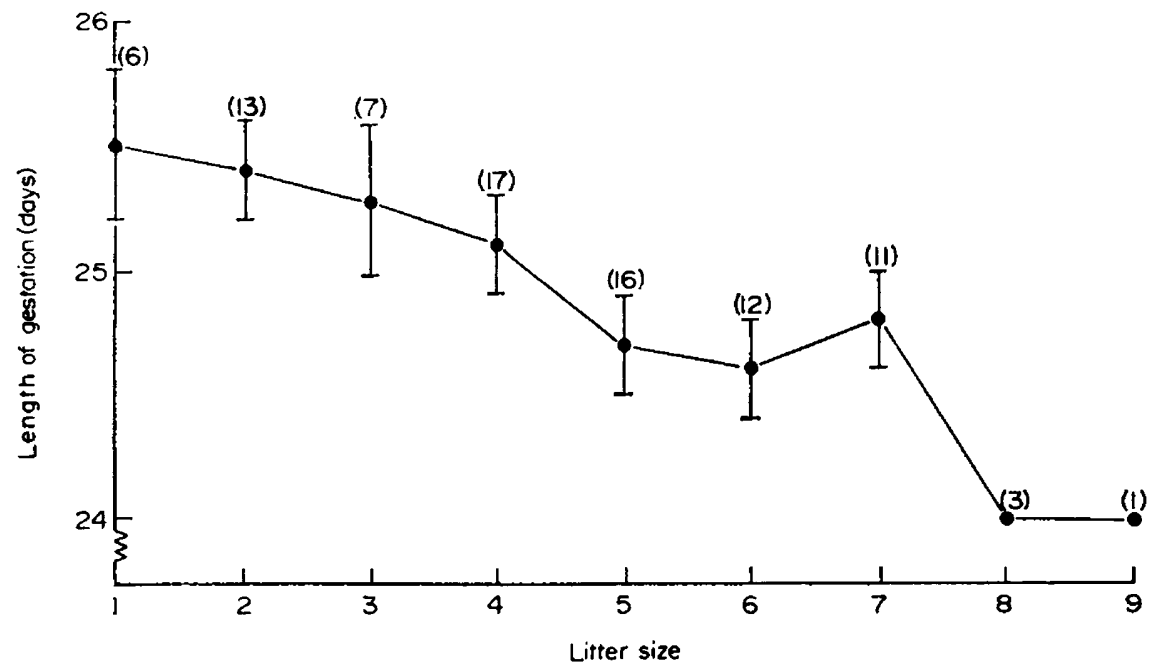

TExT-FIG. 2. The relationship between length of gestation and litter size in the Mongolian gerbil, Meriones unguiculatus. Vertical bars represent S.E. Numbers of observations are given in parentheses.

We are indebted to Dr J. H. Marston for kindly supplying us with the foundation stock.

\section{REFERENCES}

Marston, J. H. \& Ghang, M. C. (1965) The breeding, management and reproductive physiology of the Mongolian gerbil (Meriones unguiculatus). Lab. Anim. Care, 15, 34.

Nakay, K., Nimura, H., Tamura, M., Shimizu, S. \& Nishimura, H. (1960) Reproduction and post natal development of colony bred Meriones unguiculatus. Bull exp. Anim., Tokyo, 9, 157.

Norris, M. L. \& Adams, G. E. (1971) Delayed implantation in the Mongolian gerbil, Meriones unguiculatus. F. Reprod. Fert. 27, 486.

Norris, M. L. \& Adams, C. E. (1972a) The growth of the Mongolian gerbil, Meriones unguiculatus, from birth to maturity. F. Zool., Lond. 166, 277.

Norris, M. L. \& ADAms, G. E. (1972b) Aggressive behaviour and reproduction in the Mongolian gerbil, Meriones unguiculatus, relative to age and sexual experience at pairing. $\mathcal{F}$. Reprod. Fert. 31, 447.

Norris, M. L. \& Adams, G. E. (1972c) Incidence of cystic ovaries and reproduction in the Mongolian gerbil, Meriones unguiculatus. Lab. Anim. 6, 337.

SCHWENTKER, V. (1963) The gerbil. A new laboratory animal. Illinois Vet, 6, 5. 